\title{
Assessment of preclinical students' academic motivation before and after a three-day academic affair program
}

This article was published in the following Dove Press journal:

International Journal of General Medicine

I5 December 2015

Number of times this article has been viewed

\section{Myo Nyein Aung' Juraiporn Somboonwong ${ }^{2}$ Vorapol Jaroonvanichkul' Pongsak Wannakrairot ${ }^{3}$ \\ 'Medical Education Unit, ${ }^{2}$ Quality Management Division and Department of Physiology, ${ }^{3}$ Academic Affairs Division, Faculty of Medicine, Chulalongkorn University, Bangkok, Thailand}

Video abstract

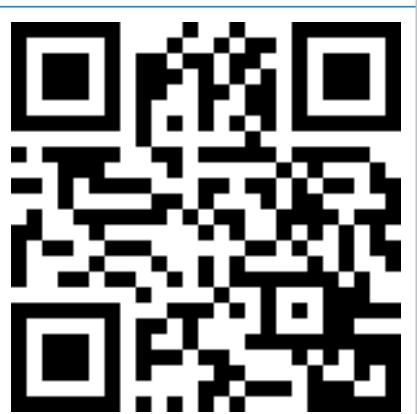

Point your SmartPhone at the code above. If you have a QR code reader the video abstract will appear. Or use: http://youtu.be/GyFvoojuZMo
Correspondence: Myo Nyein Aung WHO Collaborating Center for Medical Education, Medical Education Unit, Ananda Mahidol Building, Faculty of Medicine, Chulalongkorn University, 1873 Henri Dunant Road, Pathumwan, Bangkok 10330, Thailand

Email dr.myonyeinaung@gmail.com
Background: Medical students' motivation is an important driving factor for academic performance, and therefore medical teachers and educators are often highly interested in this topic. This study evaluated the impact of an academic affair program upon preclinical year medical students' motivation to study.

Design and methods: An intervention study was conducted using a pretest-posttest study design. A total of 296 preclinical year medical students who had just passed their first year and were about to attend their second year at the Faculty of Medicine, Chulalongkorn University, Bangkok, Thailand, participated in the study. The intervention comprised of dialogues for personality development, pictorial expression in groups, as well as small group lectures delivered by senior students giving information on how to prepare for the forthcoming classes. Students' academic motivation was measured before and after the intervention program, applying the transculturally translated Academic Motivation Scale (AMS). Cronbach's alpha of Thai version AMS was 0.8992. The average scores in seven scales of AMS were compared between the pre- and posttest results, using the Wilcoxon signed-rank test. The differences were confirmed by using the multivariate analysis of variance.

Results: Students' academic motivation increased after participation in the three-day academic program. There was also a significant increase in introjected extrinsic motivation, which can enhance the students' self-esteem and feeling of self-worth $(P<0.001)$. Moreover, intrinsic motivation toward accomplishment increased significantly $(P<0.001)$. This is related to the enjoyment of passing academic milestones, and a step ahead of autonomous motivation. Amotivation level declined significantly $(P<0.001)$. The change of academic motivational constructs before and after the intervention was altogether significant ( $P=0.036$, multivariate analysis of variance).

Conclusion: After experiencing a three-day intervention, the new students' motivation advanced along the continuum of self-determination toward autonomous motivation. Therefore, it is considered to be worthwhile conducting an academic intervention to catalyze the evolution of preclinical year medical students' academic motivation. Moreover, educators and faculties should evaluate the impact of interventions in evidence-based approaches to secure both controlled and autonomous types of motivation.

Keywords: medical education, motivation, Academic Motivation Scale, intervention, AMS, medical students

\section{Introduction}

Motivation is the source of effort which leads to human achievements. It is particularly relevant within academic institutions where students' hard work and performance are geared to achieving individual and institutional goals. ${ }^{1}$ One such example is in the academic milieu of medical schools. 
Among a number of theories regarding human motivation, the theory most relevant to medical education is the selfdetermination theory. ${ }^{2,3}$ This theory divides motivation into two different types; "extrinsic" and "intrinsic" motivation. When students are motivated extrinsically, they enjoy striving toward rewards and goals which may range from individual goals (eg, goals relating to grades, passing exams, career achievement, and salary) to institutional goals (eg, goals relating to competence, skills, personality development, and professionalism). ${ }^{4}$ Such motivation can lead to an increase in effort to achieve these rewards, however, it may also cause greater anxiety and a poor ability to cope with failure. ${ }^{4}$ Intrinsically motivated students on the other hand, enjoy exploration, learning, and curiosity-driven academic efforts. ${ }^{4}$ Such motivation is more autonomous and related to self-directed learning. Intrinsic motivation is also associated with an increased ability to cope with failure. ${ }^{5}$

Within medical education, it is therefore important to facilitate the evolution of medical students' motivation toward the autonomous stage. ${ }^{2}$ However, motivating learners is clearly, not a straight forward task. Few studies have investigated and evaluated an intervention program that seeks to facilitate students' motivation. Recently published literature reviews by Kusurkar et al revealed the necessity of research being conducted with regard to motivation, in order to fill the gap in medical education literature. ${ }^{6,7}$ Our current study is expected to fill this gap.

The Faculty of Medicine at the Chulalongkorn University regularly provides a three-day program intending to enable preclinical year students the ability to cope with the challenges of their forthcoming medical studies, and this is organized prior to the initiation of the preclinical year classes. In the current study, we have attempted to evaluate how this academic program impacted upon the motivational changes of new learners in medicine. The objectives were: 1) to describe students' academic motivation at the beginning of their medical studies; 2) to determine the change in the level of motivation before and after the three-day program; and 3) to describe students' expectations of their medical careers. It is anticipated to be the first research of its kind in Thailand and within Thailand's neighboring countries. We believe that the current study could benefit medical education by contributing evidence-based information toward the design of future intervention strategies and to motivate new learners in medicine.

\section{Design and methods} Ethical consideration

The current study was ethically approved by the Institutional Review Board of the Faculty of Medicine, Chulalongkorn
University (approval number Med Chula IRB 643/2557). Participants' written informed consent was obtained after a thorough explanation of the study. The participants were informed that their decision to take part in the research would have no impact on their academic scores, and that they could freely decide whether or not to participate in the research. Their rights and privacy were reserved and their personal information was carefully secured. Code numbers instead of names were used to collect and record the data. After the collection of the data, all data were kept secured with a password accessible only to investigators.

\section{Study design, study population, and setting}

The current study used a pretest-posttest design in order to evaluate the intervention program. The study population comprised of 296 second year medical students who had just completed their first year course work and were about to commence their preclinical year of study at the Faculty of Medicine, Chulalongkorn University, Bangkok, Thailand. The study period (from the proposal until completion of analysis), was from June 3, 2014 to November 30, 2014. The Faculty of Medicine, Chulalongkorn University, Bangkok, Thailand acted as the study setting, and is ranked as one of the top medical schools, as well as the second oldest, in Thailand. Its undergraduate medical curriculum is a 6-year long, outcome-based curriculum, designed to nurture both the personal and professional development of medical students. The first-year curriculum comprises of several components in personal development, general science, and social science. In the following two preclinical years, students learn basic medical science subjects, and in the remaining 3 years they learn the clinical subjects.

\section{Sample size}

Out of the 299 whom were invited, a total of 296 students participated in the study. This was a sufficient sample size for the power of $80 \%$ and effect size 0.2 . Statistical significance was decided as a $P$-value of $<0.05$. The power of the sample size was adequate to compare the average levels of motivation in the pre- and posttest study design. Moreover, the sample size was sufficient to compensate for a nonresponse rate of $20 \%$.

\section{Measurement}

Self-administered questionnaires were used in order to collect the data. A pretest survey was conducted on day 1 (prior to starting the program) during the trip to the venue where 
the three-day program was implemented. A posttest survey was conducted upon completion of the program before the students left the camp at the end of day 3.

Participants were carefully requested not to discuss the research with each other during data collection. The chance of answering the questionnaires to favor teachers was minimized because of the facts: 1) the researchers were not the teachers of participants; 2) the instrument applied in this study, Academic Motivation Scale (AMS), was not a simple and straightforward one which would allow the participants to guess the researcher's preference. Furthermore, prior to data collection it was thoroughly explained to the participants that neither participation nor the participants' response would impact on the student's grades.

Furthermore, participants autonomy and privacy were well protected by not including names in the data collection. Students' identification numbers were recoded to be research identification numbers before the data were keyed in. Non-faculty staff members of the Academic Affairs Division distributed and collected the questionnaires. These measures were carefully applied to control the threat to validity, caused by the respondent errors. Besides measuring motivation by AMS, students were asked to mark the level of their perceived motivation to become a medical doctor on a visual analog scale of a $10 \mathrm{~cm}$ line.

\section{Instrument}

The transculturally translated standard AMS, was applied to measure motivation, the dependent variables of interest. ${ }^{8}$ Instrument translation followed the World Health Organization recommended standard procedures: 1) forward translation; 2) back translation; 3) comprehension and readability test; and 4) final version., ${ }^{9,10}$ The translated instrument was tested for comprehension and readability by a small group comprising medical students from a different batch.

The AMS is a 28-item, 7-pointed Likert scale, as described by Vallerand et al. ${ }^{8}$ This freely available instrument is approved for use in research. ${ }^{11}$

The AMS comprises seven subscales based on the selfdetermination theory. ${ }^{8}$ Each subscale has four items and an average of each subscale was taken as the score. The subscale measures are as follows: 1) intrinsic motivation to know (the enthusiasm to acquire new knowledge); 2) intrinsic motivation toward accomplishment (the satisfaction in completing work); 3) intrinsic motivation to experience stimulation (the motivation to learn new things and to experience the learning process itself); 4) extrinsic motivation-identified regulation (the motivation resulting from external factors such as personal goals, institutional goals, or national goals);
5) extrinsic motivation-introjected regulation (the motivation resulting from the desire to prove one's ability in order to achieve rewards); 6) extrinsic motivation external regulation (the drive to try to and achieve rewards, such as an improved academic grade, a degree, or a higher salary); and 7) amotivation (the absence of intent or drive to engage in an activity, whether this is due to a lack of perceived competence and/ or a lack of value in its outcomes). The construct of AMS has been evidence-supported with its validity and reliability tested and proven in several previous studies, ${ }^{12}$ as well as within research undertaken in medical schools. ${ }^{13,14}$

The current study adopted the AMS in a systematic way to preserve the validity. Cronbach's alpha of 0.8992 indicated the reliability and internal consistency of Thai version AMS within the current study population.

\section{Intervention}

The intervention in the current study comprised a three-day long program arranged by the Academic Affairs Division, Faculty of Medicine, Chulalongkorn University, Thailand. All medical students who had completed their first-year course and were about to start their preclinical years attended a program called the Ton-gla program (Ton-gla means "new sprout" in Thai). The location of the program was at a resort outside of Bangkok. The program aimed to trigger and enhance the new medical students' motivation. Table 1 outlines the three-day program.

\section{Day I program included:}

1. Personal development talk by the personal development expert;

2. Talk on how to ignite desire to become a doctor, and social expectation towards doctors;

3. Drawing illustration in groups to express how they foresee future of Medicine.

\section{Day 2 program included:}

1. Talk on how to enjoy the preclinical years;

2. A case scenario about coping with stress;

3. MDCU "Got Talent", a talent show of student performances.

\section{Day 3 program included:}

1. Talk on seeking the identity of MDCU 69 students (69th batch of Faculty of Medicine students). The program was designed by a committee of experienced medical teachers, with faculty members after stakeholder meetings emphasizing not only academic strategy but also contextual determinants in Thai society. 
Table I Details of the intervention program before beginning second year preclinical curriculum at Faculty of Medicine, Chulalongkorn University, Bangkok, Thailand in 2014

\begin{tabular}{|c|c|c|c|}
\hline Day & Time & Type of activity & Expected results \\
\hline \multirow[t]{9}{*}{ Day 1} & $10 \mathrm{am}$ to & Dialogues by the expert in personality development: & Personality development to be a good doctor \\
\hline & $12 \mathrm{pm}$ & How to behave as a good doctor & \\
\hline & & Theory and practice of personality development & \\
\hline & I pm to & Interactive talks and discussion by two psychiatrists: How & To understand social value of the doctors \\
\hline & $5 \mathrm{pm}$ & to ignite the desire to become a doctor expected by the society & To adapt to ever-growing knowledge in medicine, \\
\hline & & Small group discussion of students about the future of medicine & medical science, and medical technology \\
\hline & & Pictorial expression: drawing pictures in groups & \\
\hline & $7 \mathrm{pm}$ to & Group work: "How to enjoy preclinical years" (Part I) & To recognize the importance of basic medical \\
\hline & $9 \mathrm{pm}$ & $\begin{array}{l}\text { Students acquired information from faculties } \\
\text { and senior students }\end{array}$ & $\begin{array}{l}\text { subjects: Introducing the nature of subjects, teaching } \\
\text { and learning approaches, and the significance of } \\
\text { preclinical subjects in medicine }\end{array}$ \\
\hline \multirow[t]{7}{*}{ Day 2} & 8 am to & Group work "How to enjoy preclinical Years" (Part 2): Each & To recognize the importance of basic medical \\
\hline & $12 \mathrm{pm}$ & group analyzed and summarized the results & subjects: Introducing the nature of subjects, teaching \\
\hline & & Making poster and poster presentation & and learning approaches, and the significance of \\
\hline & & Selection for best poster award & preclinical subjects in medicine \\
\hline & I pm to & Case scenario of coping with stress in preclinical years: & To understand: I) the academic steps which would \\
\hline & $4 \mathrm{pm}$ & $\begin{array}{l}\text { Small group discussion of students facilitated by faculty } \\
\text { staff }\end{array}$ & $\begin{array}{l}\text { be experienced in preclinical years; 2) appropriate } \\
\text { behavior to use social media; 3) the disciplines; and } \\
\text { 4) how to avoid academic cheating }\end{array}$ \\
\hline & $\begin{array}{l}7 \mathrm{pm} \text { to } \\
9 \mathrm{pm}\end{array}$ & $\begin{array}{l}\text { MDCU “Got Talent”: A talent show of medical students } \\
\text { where students perform singing, dancing, aerobics, } \\
\text { cheerleading, drumming, or martial arts }\end{array}$ & $\begin{array}{l}\text { An opportunity to express students' leadership, } \\
\text { teamwork, and creativity }\end{array}$ \\
\hline \multirow[t]{3}{*}{ Day 3} & 8 am to & Competitive debate: Teams debate & To find out what should be appropriate behaviors of \\
\hline & 12 noon & Summary presented by the team leaders & medical students, and develop their code of conduct \\
\hline & & Selection of the best one & \\
\hline
\end{tabular}

Notes: MDCU means a batch of students studying at Faculty of Medicine, Chulalongkorn University, to become Doctor of Medicine. "MDCU Got Talent" was the name of talent show which was part of the intervention program.

Abbreviation: AMS, academic motivation scale.

Table 2 Characteristics of the students $(\mathrm{N}=296)$

\begin{tabular}{lll}
\hline Characteristics & Number & Percent \\
\hline Age (years) & 28 & \\
18 & 228 & 9.46 \\
19 & 37 & 77.03 \\
20 & 2 & 12.05 \\
21 & 1 & 0.68 \\
24 & & 0.34 \\
Sex & 162 & \\
Male & 134 & 54.73 \\
Female & & 45.27 \\
Living place & 6 & \\
In campus dormitory & 286 & 2.03 \\
Outside campus & 4 & 96.62 \\
No response & & 1.35 \\
Having a doctor in the family & 126 & \\
Yes & 166 & 43.92 \\
No & 4 & 56.08 \\
No response & & 1.35 \\
Scholarship & 16 & \\
Full & 10 & 5.41 \\
Partial & 263 & 3.38 \\
No & 7 & 88.85 \\
No response & & 2.36 \\
Province of origin & 165 & \\
Bangkok & 131 & 55.74 \\
Outside Bangkok & & 44.26 \\
Graduated high school & 14 & \\
Private school & 271 & 9.7 \\
Public school & 11.6 \\
No response & & 3.7 \\
\hline
\end{tabular}

\section{Analysis}

Baseline demographic data was analyzed descriptively. The average scores in the seven subscales of the AMS were compared between pretest and posttest results applying the Wilcoxon signed-rank test. The differences were confirmed using multivariate analysis of variance MANOVA ${ }^{15}$ in Stata version 11 (Stata Corporation, College Station, TX, USA). The level of significance was set at $P<0.05$ at $95 \%$ confidence interval.

\section{Results}

\section{Students' characteristics}

The response rate of the base line survey was $99 \%$. The median age of the participants was 19 years. Female students comprised of $54.27 \%$ of the class. Most of the students in the study either lived at home or in dormitories outside of the university campus. Almost half (43\%) of the students had a doctor in their family. Less than $20 \%$ of the students attending medical school had a scholarship. Table 2 represents the students characteristics.

\section{Career expectation of the preclinical year medical students}

The career expectation among the vast majority of the medical students (250 students [84.5\%]) was to become a 


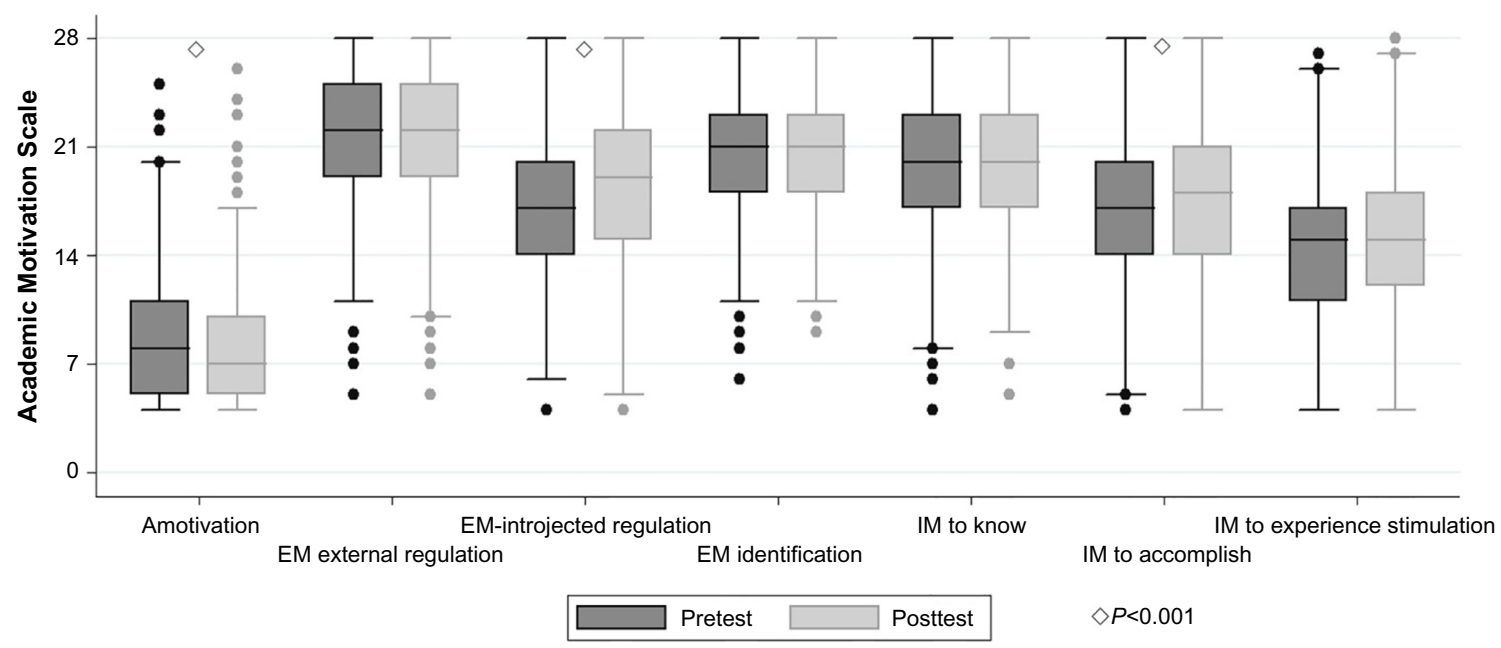

Figure I Box and whisker plots showing distribution of base line and post intervention levels of Academic Motivation Scale.

Note: From left to right, the constructs are in the order of the least autonomous (amotivation) to the most autonomous (IM to experience stimulation), showing the continuum of self-determination theory.

Abbreviations: IM, intrinsic motivation; EM, extrinsic motivation.

specialist clinician, while most of the remaining students (40 students [13.5\%]) answered that they wanted to become a general practitioner. When asked to choose their preferred career out of three options (medical teacher, researcher, or clinician), the majority of the new medical students $(255$ students [86.1\%]) chose clinician, whereas 25 students $(8.4 \%)$ chose medical teacher, and 12 students $(4.1 \%)$ chose researcher.

Table 3 Changes in academic motivation constructs among second year medical students, before and after a three-day intervention program, implemented before beginning preclinical curriculum

\begin{tabular}{|c|c|c|c|c|}
\hline \multirow[t]{2}{*}{ Subscale of AMS } & \multirow{2}{*}{$\frac{\text { Pretest }}{\text { Med (IQR) }}$} & \multirow{2}{*}{$\frac{\text { Posttest }}{\text { Med (IQR) }}$} & \multirow[t]{2}{*}{$P$-value } & \multirow[t]{2}{*}{$\mathbf{n}$} \\
\hline & & & & \\
\hline \multicolumn{5}{|l|}{ Assessment results } \\
\hline \multicolumn{5}{|l|}{ Univariate analysis } \\
\hline $\begin{array}{l}\text { IM to experience } \\
\text { stimulation }\end{array}$ & $15(11-17)$ & $15(12-18)$ & 0.23 & 290 \\
\hline $\begin{array}{l}\text { IM toward } \\
\text { accomplishment }\end{array}$ & $17(14-20)$ & $18(|4-2|)$ & $<0.00$ I & 289 \\
\hline IM to know & $20(17-23)$ & $20(17-23)$ & 0.60 & 290 \\
\hline EM identification & $21(18-23)$ & $21(18-23)$ & 0.11 & 292 \\
\hline EM introjected regulation & $17(14-20)$ & $19(15-22)$ & $<0.001$ & 291 \\
\hline EM external regulation & $22(19-25)$ & $22(19-25)$ & 0.28 & 292 \\
\hline Amotivation & $8(5-11)$ & $7(5-10)$ & $<0.001$ & 290 \\
\hline \multicolumn{5}{|c|}{ Multivariate analysis of variance } \\
\hline $\begin{array}{l}\text { Difference in seven } \\
\text { constructs of AMS } \\
\text { by intervention }\end{array}$ & & & $0.036^{\mathrm{a}}$ & \\
\hline
\end{tabular}

Notes: ${ }^{2}$ Statistical significance by multivariate analysis of variance. Statistical significance by $P$-value of Wilcoxon signed-rank test unless specified as other. Subscale are in the vertical order of self-determination continuum from the least autonomous (amotivation) at the bottom of the table, to the most autonomous (intrinsic to experience stimulation) at the top of the table.

Abbreviations: Med, median; IQR, interquartile range; IM, intrinsic motivation; EM, extrinsic motivation;AMS, academic motivation scale; $n$, sample size in each analysis.

\section{Pre- and posttest assessment of medical students academic motivation}

According to baseline data relating to external motivation introjection, the levels of the extrinsic motivation constructs were higher than the levels of all three intrinsic motivation constructs. Extrinsic motivation identification and extrinsic motivation external regulation were the two highest level constructs, while among the intrinsic motivation constructs, intrinsic motivation to experience stimulation was the lowest level construct (Figure 1 and Table 3).

After the intervention, intrinsic motivation to accomplish $(P<0.001)$ and external motivation introjection $(P<0.001)$ increased significantly, whereas amotivation decreased significantly $(P<0.001)$ (Table 3$)$.

The effect of the intervention was confirmed by comparing all of the dependent variables in a multivariate analysis of variance model. It was statistically significant $(P=0.036)$. Moreover, self-assessment of motivation, measured by visual

Table 4 Visual analog scale self-assessment of motivation to study to be a medical doctor, before and after a three-day intervention program

\begin{tabular}{llllll}
\hline $\begin{array}{l}\text { Self assessment } \\
\text { of academic } \\
\text { motivation }\end{array}$ & Pretest & & Posttest & P-value & $\mathbf{n}$ \\
& Med (IQR) & & Med (IQR) & & \\
\hline VAS to become an MD & $6.9(5.6-8)$ & $7.2(6-8.25)$ & $<0.001$ & 288 \\
VAS to become & $7.15(6-8.3)$ & $7.45(6.25-8.55)$ & $<0.00$ I & 288 \\
a specialist & & & & \\
\hline
\end{tabular}

Note: Statistical significance by $P$-value of Wilcoxin signed-rank test.

Abbreviations: VAS, visual analog scale; Med, median; IQR, interquartile range; MD, Doctor of Medicine. 
analog scale, was found to increase significantly after the intervention (Table 4).

\section{Discussion}

The current study is an interventional study conducted using a quasi-experimental study design. In this study all the students were new to the medical curriculum and were about to commence the study of their preclinical subjects. The intervention was launched prior to the beginning of the new courses. The findings in this study confirmed that there were significant increases in extrinsic motivation, as well as intrinsic motivation, confirmed by a multivariate analysis of variance $(P=0.036)$ (Table 3$)$. It has been shown that improvements in academic motivation can be facilitated by a properly designed intervention. Moreover, since motivation is the driver of academic performance, it is worthwhile conducting such an intervention at the very beginning of the medical curriculum, as it may in turn lead to higher levels of industriousness. ${ }^{13}$

The baseline measurement showed that preclinical year students are highly motivated, and details of the sub scores indicated a high level of extrinsic motivation (Figure 1). This is also supported by the students reporting their motivation to be specialists, according to visual analog scale measurement (Table 4). Most of the medical students have the high career goal to become clinical specialists, which requires many years of hard work at medical school. These findings revealed the characteristic pattern of preclinical students' motivation coupled with a high degree of reward-based controlled motivation. ${ }^{16}$

A careful analysis of the AMS sub scores reflected the actual impact of the intervention program. After intervention, the average score of intrinsic motivation toward accomplishment was promoted significantly $(P<0.001)$ (Table 3$)$. This indicates the learners' motivation to overcome difficult academic duties and strive for excellence in their medical studies. ${ }^{12}$ The average score in extrinsic motivation-introjected regulation also increased significantly after the intervention program $(P<0.001)$ (Table 3$)$. It revealed the students' motivation to attain success in completing their medical degrees, and proved their efficacy was catalyzed by the intervention program. $^{12}$

Moreover, amotivation decreased significantly. This indicates that the explanation regarding the preclinical year curriculum, given in the intervention, served to delineate any unclear vision and goals experienced by the new learners. ${ }^{12}$ The program may have triggered students' engagement with the orientation of the forthcoming curriculum and this represents an important and basic step for the academic success of undergraduate students (Table 1). ${ }^{17}$

Previous studies have reported that introjected external motivation can maximize the learner's efforts, but it could also lead to an increase in anxiety and the poor ability to cope with failures. ${ }^{18}$ In the concept of the self-determination theory, an individual's motivation may progress from controlled extrinsic motivation to internal motivation, and finally to autonomous motivation. ${ }^{4}$ Internal motivation to experience stimulation is the most autonomous phase of development within the continuum of the self-determination theory (Figure 1)..$^{5}$

Compared to controlled motivation, intrinsic motivation is associated with a happier and healthier academic approach, leading to an ability to positively cope with failures. ${ }^{4,16}$ Previously, a meta-analysis reported that tangible rewards, threats, deadlines, and competitive pressure could undermine intrinsic motivation. ${ }^{19}$ Therefore, to target a balance between these two types of motivation is an important expectation in designing an intervention to facilitate medical students' motivation.

Overall, the intervention program in the current study achieved a satisfactory balance between these targets (Figure 1). The level of "intrsinsic motivation to experience stimulation" was lower than the other subscores according to baseline measurements (Figure 1), and it did not increase significantly after the intervention program. This indicates the need for further facilitation of autonomous motivation among medical students. The low level of this sub score, however, could be due to the fact that the participants were new medical students and were naïve to the experience of a medical curriculum as the intervention was launched prior to the beginning of the curriculum. Further experience of the medical curriculum and its activities may increase the students' motivation, helping to internalize extrinsic motivation and ultimately make it autonomous. It also largely depends on how interesting the curriculum design is, whether there is an autonomy-favored learning environment, how much positive feedback in the assessment is given, and to what extent is there inherent interest in the medical subjects. ${ }^{3,20,21}$

Moreover, the type and level of the medical students' motivation may change when they are exposed to patients in the clinical wards, to the community setting where they learn public health, and when they start practicing medicine in an internship. Spaced interventions and repeated assessment of academic motivation in later years of medical school may answer these questions, and it will require following up 
medical students from when they begin medical school until they graduate.

A continuation of well-designed intervention programs to facilitate such internal motivation is necessary. ${ }^{21}$ Therefore, to assist in facilitating the evolution of medical learners' motivation, future research should focus on longitudinal observational studies in order to determine whether autonomous motivation can be achieved in successive academic years, and the factors that influence this internalization. ${ }^{13}$

\section{Limitations and strengths}

The current study was designed to evaluate the intervention program. However, it lacked a control group because excluding some students as control was not appropriate in the nature of educational intervention. ${ }^{22}$ The findings of the current study were strengthened by the power of an adequate sample size, the quality of outcome measurement applying standard instruments, and careful analysis using uni- and multivariate approaches. ${ }^{15,23}$ Apart from the motivational impact analyzed in this research, the intervention may provide orientation and guidance to students making academic, personal, and social adjustments to medical student life. ${ }^{24}$

\section{Conclusion}

New learners' motivation can be promoted by a well-designed intervention within the context of medical education. A brief academic affairs program could enhance the academic motivation of medical students by providing clear orientation, visible challenges to pass, and embedded social values of the medical profession. The intervention reported in this research may form a reproducible example, especially for undergraduate medical schools in Asia. Moreover, educators and faculties should evaluate the impact of the intervention in evidence-based approaches, to secure both controlled and autonomous types of motivation.

\section{Acknowledgments}

This research is supported by Rachadapisek Sompot Fund for Postdoctoral Fellowship, Chulalongkorn University. Associate Professor Prida Tasanapradit, Professor Sompop Limpongsanurak, and Dr Danai Wangsaturaka are acknowledged for their important advice in conducting this medical educational research and revising the manuscript. The study may not have been made possible without the kind support of Pajaree Yenbutra, the WHO Collaborating Center for Medical Education, and staff from the Academic Affairs, who helped with survey administration. MDCU 69 batch students of the
Faculty of Medicine, Chulalongkorn University are heartily acknowledged for their active engagement in the research.

\section{Disclosure}

The authors report no conflicts of interest in this work.

\section{References}

1. Mann KV. Motivation in medical education: how theory can inform our practice. Acad Med. 1999;74(3):237-239.

2. Williams GC, Saizow RB, Ryan RM. The importance of selfdetermination theory for medical education. Acad Med. 1999;74(9): 992-995.

3. Lyness JM, Lurie SJ, Ward DS, Mooney CJ, Lambert DR. Engaging students and faculty: implications of self-determination theory for teachers and leaders in academic medicine. BMC Med Educ. 2013;13(1):151.

4. Ryan RM, Deci EL. Intrinsic and extrinsic motivations: classic definitions and new directions. Contemporary Educational Psychology. 2000;25(1):54-67.

5. Ryan RM, Connell JP. Perceived locus of causality and internalization: examining reasons for acting in two domains. J Pers Soc Psychol. 1989;57(5):749-761.

6. Kusurkar RA, Croiset G, Mann KV, Custers E, Ten Cate O. Have motivation theories guided the development and reform of medical education curricula? A review of the literature. Acad Med. 2012;87(6):735-743.

7. Kusurkar RA, Ten Cate TJ, van Asperen M, Croiset G. Motivation as an independent and a dependent variable in medical education: a review of the literature. Med Teach. 2011;33(5):e242-e262.

8. Vallerand RJ, Pelletier LG, Blais MR, Briere NM, Senecal C, Vallieres EF. On the assessment of intrinsic, extrinsic, and amotivation in education: evidence on the concurrent and construct validity of the academic motivation scale. Educational and Psychological Measurement. 1993;53(1):159-172.

9. World Health Organization [homepage on the Internet]. WHO: Process of translation and adaptation of instruments [updated 2014]. Available from: http://www.who.int/substance_abuse/research_tools/translation/ en/. Accessed April 30, 2014.

10. Maneesriwongul W, Dixon JK. Instrument translation process: a methods review. $J A d v$ Nurs. 2004;48(2):175-186.

11. Laboratoire De Rescherche Sur Le Comportment Social: Academic Motivation. (2014). Available from: http://www.er.uqam.ca/nobel/ r26710/LRCS/echelles_en.htm. Accessed May 26, 2015.

12. Kusurkar R, Croiset G, Kruitwagen C, ten Cate O. Validity evidence for the measurement of the strength of motivation for medical school. Adv Health Sci Educ Theory Pract. 2011;16(2):183-195.

13. Del-Ben CM, Machado VF, Madisson MM, Resende TL, Valério FP, Troncon LE. Relationship between academic performance and affective changes during the first year at medical school. Med Teach. 2013;35(5):404-410.

14. Park J, Chung S, An H, et al. A structural model of stress, motivation, and academic performance in medical students. Psychiatry Investig. 2012;9(2):143-149.

15. Gaddis ML. Statistical methodology: IV. Analysis of variance, analysis of covariance, and multivariate analysis of variance. Acad Emerg Med. 1998;5(3):258-265.

16. Sobral DT. What kind of motivation drives medical students' learning quests? Med Educ. Sep 2004;38(9):950-957.

17. Celia Popovic, Green DA. Understanding Undergraduates: Challenging Our Preconceptions of Student Success. London: Routledge; 2012.

18. Kusurkar RA, Croiset G, Galindo-Garre F, Ten Cate O. Motivational profiles of medical students: association with study effort, academic performance and exhaustion. BMC Med Educ. 2013;13(1):87.

19. Deci EL, Koestner R, Ryan RM. Extrinsic rewards and intrinsic motivation in education: reconsidered once again. Review of Educational Research. 2001;71(1):1-27. 
20. Lavigne GL, Vallerand RJ, Miquelon P. A motivational model of persistence in science education: a self-determination theory approach. European Journal of Psychology of Education. 2007;22(3):351-369.

21. Kusurkar RA, Croiset G, Ten Cate TJ. Twelve tips to stimulate intrinsic motivation in students through autonomy-supportive classroom teaching derived from Self- Determination Theory. Med Teach. 2011;33(12):978-982.

22. Wong G, Greenhalgh T, Westhorp G, Pawson R. Realist methods in medical education research: what are they and what can they contribute? Medical Educ. 2012;46(1):89-96.
23. Tonidandel S, LeBreton JM. Beyond step-down analysis: a new test for decomposing the importance of dependent variables in MANOVA. J Appl Psychol. 2013;98(3):469-477.

24. Hanifi N, Parvizy S, Joolaee S. Motivational journey of Iranian bachelor of nursing students during clinical education: a grounded theory study. Nurs Health Sci. 2013;15(3):340-345.

\section{Publish your work in this journal}

The International Journal of General Medicine is an international, peer-reviewed open-access journal that focuses on general and internal medicine, pathogenesis, epidemiology, diagnosis, monitoring and treatment protocols. The journal is characterized by the rapid reporting of reviews, original research and clinical studies across all disease areas.
A key focus is the elucidation of disease processes and management protocols resulting in improved outcomes for the patient. The manuscript management system is completely online and includes a very quick and fair peer-review system. Visit http://www.dovepress.com/ testimonials.php to read real quotes from published authors.

Submit your manuscript here: http://www.dovepress.com/international-journal-of-general-medicine-journal 